\title{
Documentation of special foods given to promote lactation district of Uttarakhand in Almora
}

\author{
Dinu Kumari and Pushpa Bharati
}

An investigation was undertaken on 60 mothers of Almora district to document special foods given to promote lactation. Milk with ghee was consumed by more than 50 per cent of the pregnant women prior to delivery. Most common special foods given during lactation upto first week were ginger kada, black tea and ajwain kada while, atta ka halwa was consumed during second week (58). Consumption of dalia (56), Moong dhal khichadi (36) and milk with honey (10) was slowly reduced from first week to third month. Normal diet was resumed after one month. Mothers consumed lesser quantity of water when the girl baby was born as compared to boy baby. Avoidance of fast foods (57), garlic (46), pumpkin (45), onion (44), brinjal (43), green chilies (43) and pickle (30) were reported by majority of the mothers from Almora.

Key Words : Lactation, Special foods, Atta ka halwa, Methi ladoo, Panjiri

How to cite this article : Kumari, Dinu and Bharati, Pushpa (2020). Documentation of special foods given to promote lactation district of Uttarakhand in Almora. Food Sci. Res. J., 11(2): 108-114, DOI : 10.15740/HAS/FSRJ/11.2/108-114.Copyright@ 2020: Hind Agri-Horticultural Society. 